Jurnal Teknologi Kedirgantaraan, Vol, VI No. 2, Agustus 2021, P-ISSN 2528-2778, E-ISSN 2684-9704

https://doi.org/10.35894/jtk.v6i2

\title{
Modal Analysis Of Blended Wing-Body UAV
}

\author{
Neno Ruseno (1) * \\ [1]International University Liaison Indonesia, My Republic Plaza, 5th Floor, BSD City, Tangerang, Banten \\ 15345, Indonesia \\ *Corresponding Author: neno.ruseno@iuli.ac.id
}

\begin{abstract}
The modal analysis deals with the dynamic behavior of mechanical structures under the dynamic vibration. This study aims to analyze the vibration characteristic of the blended wing-body Unmanned Aerial Vehicle (UAV) using modal analysis. The numerical method is used to calculate the eigen frequencies of the system. The COMSOL Multiphysics is selected as the Finite Element Method (FEM) software to simulate the study. The resulted eigen frequencies are $278.05 \mathrm{~Hz}, 721.28 \mathrm{~Hz}, 816.39 \mathrm{~Hz}, 1601.7 \mathrm{~Hz}$, $1699.5 \mathrm{~Hz}$, and $1855.5 \mathrm{~Hz}$. The study also evaluates the displacement of the leading edge of the wing in all axes to understand the modal shapes. The modal shapes found are updrift, swift back, flapping vertical, flapping horizontal, flapping opposite horizontal and flapping more wave in horizontal movement. The comparison of resulted eigen frequencies with a conventional aircraft wing is conducted to understand the difference in its vibration characteristics.
\end{abstract}

Keywords: Modal analysis, Blended Wing-Body UAV, Eigen Frequency, Modal Shape, COMSOL Multiphysics 
Jurnal Teknologi Kedirgantaraan, Vol, VI No. 2, Agustus 2021, P-ISSN 2528-2778, E-ISSN 2684-9704 https://doi.org/10.35894/jtk.v6i2

\section{Introduction}

The modal analysis deals with the dynamic behavior of mechanical structures under the dynamic excitation. The modal analysis is used to determine the dynamic characteristics of a system such as natural frequency, mode shapes etc. It is a promising candidate for flutter testing and Structural Health Monitoring (SHM) of aircraft.

Unmanned Aerial Vehicle (UAS) grows significantly in recent years. Their application can be found in many of our daily life: photography, survey, monitoring, search \& rescue, etc. There are many types of UAV such as fixed wing, rotary wing, and mix of them. Other new type of UAV is a blended wing-body. It was claimed to be more efficient in term of aerodynamic and enable more payload/space.

This study aims to analyze the vibration characteristic of the blended wing-body UAV using modal analysis. The result can be used in design the UAV to reduce the negative effect of external factors due to its vibration characteristic. This report consists of literature study in chapter 2, the background theory and methodology in chapter 3 and 4 . The result and analysis are in chapter 5 . The last chapter is the conclusion.

\section{Literature Review}

This literature study covers 6 publications focused on modal analysis of aircraft structure. The content will consist of two main parts: the methods of modal analysis and the category of aircraft part used in modal analysis.

\section{The Method of Modal Analysis}

There are two basic methods of the modal analysis, namely the experimental modal analysis and the numerical modal analysis. The experimental modal analysis deals with measurements input data from which a mathematical model is derived. While the numerical modal analysis using calculation method normally Finite Element Method calculation to solve the vibration problem.

At least, there are 3 research conducted in modal analysis using experimental method. First, ground vibration testing and flight vibration testing of aircraft as applied at DLR (the German Aerospace Center). This method is based on output only modal analysis and have been developed with specific focus on efficient certification of experimental aircraft operated by DLR [1].

The second, the HIRENASD project was a study of an elastic wing model in the transonic regime carried out in 2006. The tests were conducted at the European Transonic 55 Wind tunnel (ETW). The aeroelastic behavior of a fixed-wing model was investigated at Reynolds and Mach numbers that are typically encountered by large aircraft in cruise flight ${ }^{[2]}$.

The last is the experimental vibration analysis of the hexa-copter frame and its individual components. The experiment determined axial and radial vibration patterns, are processed so that they can be implemented in a structural numerical FE model ${ }^{[3]}$.

The other method which is Numerical method consist of 4 publications. The first publication found using a CAD model of an aircraft wing and modeling software PROE5.0. The modal analysis was carried out by using ANSYS WORKBENCH $14.0^{[4]}$. The second, the modal analysis is done using the IDEAS software. It estimated the natural frequencies and the natural mode shapes of an aircraft ${ }^{[5]}$.

The third, Finite Element (FE) model is used for construction of the whole hexa-copter. For this purpose, the center plates and the tubular arms are meshed using shell elements while the clamping blocks are meshed using 
Jurnal Teknologi Kedirgantaraan, Vol, VI No. 2, Agustus 2021, P-ISSN 2528-2778, E-ISSN 2684-9704 https://doi.org/10.35894/jtk.v6i2

volume elements ${ }^{[3]}$. The last is using FE model, originally created in NASTRAN, was converted into the SAMCEF FE software. The complete FE model has more than 80,000 DOFs [6].

\section{The Category of Aircraft Parts in Modal Analysis}

In general, modal analysis uses 2 kind of aircraft parts. The first category is aircraft wing only because the wing is considered as the aircraft part that experienced the largest vibration. The second category is using the full aircraft model.

In the Wing category, there are 2 research found. The first one using aircraft wing for investigation in A300 (wing structure consist of NACA64A215) [4]. The second research used a wing which equipped with 9 functional accelerometers and 205 functional pressure sensors distributed over 7 span-wise sections ${ }^{[2]}$.

The second category which uses full aircraft body consists of 4 publications. The modal analysis has been performed on a Do228 commuter class aircraft - one of DLR's research aircraft [1]. The second paper presents the results of the Computational Modal Analysis of a complete finite element model of the LASTA aircraft [5]. The third application considered the airframe of the Morane-Saulnier Paris aircraft [6]. The last publication analyzed the main vibration sources affecting a UAV and an experimental modal analysis of the main structural components of the multirotor chassis ${ }^{[3]}$.

\section{III.BACKGROUND THEORY}

The general vibration equation of motion in the matrix form is [5]:

$[\mathrm{M}]\{\ddot{u}\}+[\mathrm{C}]\{\dot{u}\}+[\mathrm{K}]\{u\}=\{\mathrm{P}\}$

where:

[M] - mass matrix

[C] - damping matrix

$[\mathrm{K}]$ - stiffness matrix
$\{P\}$ - force vector

$\{u\}$ - displacement vector

We can assume that the dissipative forces $[C]\{\dot{u}\}$ and the external (excitation) forces are neglected, $\{P\}=0$, the equation of motion (1) simplified to equation of motion for undamped free vibrations and its matrix form is:

$$
[\mathrm{M}]\{\ddot{u}\}+[\mathrm{K}]\{u\}=0
$$

Using the Modal Decomposition Method and the condition is a harmonic vibration $\{\ddot{u}\}=-\omega^{2}\{u\}$, eq. (2) reduces to the eigen value problem:

$$
\left([\mathrm{K}]-\omega^{2}[\mathrm{M}]\right)\{\varphi\}=0
$$

where:

$\{\varphi\}$ - eigenvector, or natural mode shape

$\omega$ - circular natural frequency

Eq. (3) is called eigen problem in a form of a set of homogeneous algebraic equations. It represents core for the eigen value problem calculation. The most important step in the dynamic analysis of the structure is to solve the characteristic equation. By premultiplying eigen eq. (3) by the matrix $[M]^{-1}$, or by the matrix $[K]^{-1}$, it can yield a standard eigen value problem:

where:

$$
[A]\{\varphi\}=\lambda\{\varphi\}
$$

$[\mathrm{A}]=[M]^{-1}[\mathrm{~K}]$ : square dynamic matrix $\lambda=\omega^{2} \quad$ : eigenvalue

The matrix $[M]^{-1}$ shall be nonsingular. A consistent mass matrix will satisfy this condition. A stiffness matrix can satisfy this condition if the rigid body motion degrees of freedom are supported. If the rigid body motion degrees of freedom available, the Shift Frequency Method [9] is applied and it yield eq. (3) to: 
where:

$$
\left(\left[\mathrm{K}^{\prime}\right]-\left(\omega^{2} \pm S^{2}\right)[\mathrm{M}]\right)\{\varphi\}=0
$$

$$
\left[\mathrm{K}^{\prime}\right]=[\mathrm{K}] \pm S^{2}[\mathrm{M}]
$$

Eq. (3), eigen equation, has two possible solutions:

1. If $\operatorname{det}\left([\mathrm{K}]-\omega^{2}[\mathrm{M}]\right) \neq 0$, the only possible solution is $\{\varphi\}=0$. This is a trivial solution, which does not give any useful information from a physical point of view, except that there is no motion.

2. If $\operatorname{det}\left([\mathrm{K}]-\omega^{2}[\mathrm{M}]\right)=0$, the solution is non-trivial $\{\varphi\} \neq 0$ and it is the important solution for our analysis.

The eigen value problem is then simplified to the following equation:

$$
\operatorname{det}\left([\mathrm{K}]-\omega^{2}[\mathrm{M}]\right)=0
$$

and for $\omega^{2}=\lambda$ is:

$$
\operatorname{det}([K]-\lambda[M])=0
$$

The determinant is zero only at the set of discrete eigen values $\lambda_{i}$, or $\omega_{i}{ }^{2}$. The corresponding i-th eigenvector is $\{\varphi\}_{i}$. Thus, the eq. (3) can be rewritten as:

$$
\left([\mathrm{K}]-\omega_{i}^{2}[\mathrm{M}]\right)\{\varphi\}_{i}=0 \mathrm{i}=1,2,3 \ldots
$$

The number of eigen values and eigen vectors is represent the number of degrees of freedom. In structural dynamics, each eigen value corresponds to the natural frequency and each eigenvector to the natural mode shape. Both define one free vibration mode of the structure. The i-th eigen value $\lambda_{i}$ is related to the $\mathrm{i}$-th natural frequency as follows:

$$
f_{i}=\frac{\omega_{i}}{2 \pi}
$$

where:

$f_{i}$ - i-th natural frequency

$\varphi_{i}=\lambda_{i}$

The mode shape of a linear elastic structure that is in free or forced vibration, at any point in time, is the sum up of all its natural mode shapes, or mathematically:

$$
\{\mathrm{u}\}=\sum_{i}\{\varphi\}_{i} \xi_{i}
$$

where:

$\{u\}$ - vector of physical displacements

$\{\varphi\}_{i} \quad$ - i-th natural mode shape

$\xi_{i} \quad$ - i-th modal displacement

\section{Methodology}

The modal analysis in this study is conducted using numerical method in COMSOL Multiphysics software. It is a cross-platform finite element analysis, solver and multiphysics simulation software. It allows conventional physics-based user interfaces and coupled systems of partial differential equations (PDEs). COMSOL provides an IDE and unified workflow for electrical, mechanical, fluid, acoustics, and chemical applications ${ }^{[7]}$.

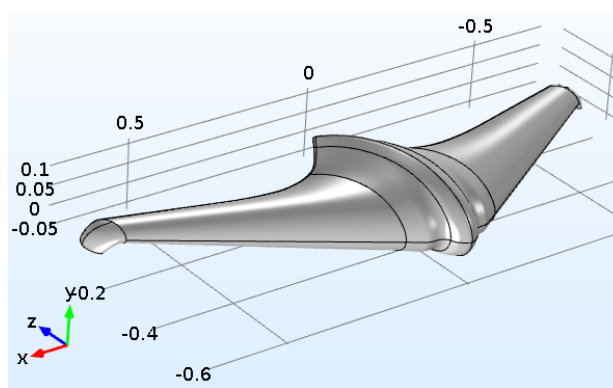

(a)

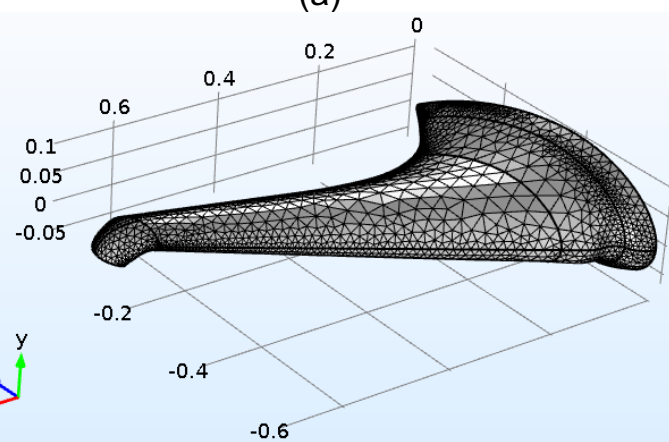

(b)

Figure 1 - Wing-body blended UAV:

(a) geometry, (b) mesh

The Physics type used in the study is Solid Mechanic with Eigen Frequency study. This module allows to conduct modal analysis of any kind of structure geometry. The geometry used is a 
Jurnal Teknologi Kedirgantaraan, Vol, VI No. 2, Agustus 2021, P-ISSN 2528-2778, E-ISSN 2684-9704 https://doi.org/10.35894/jtk.v6i2

blended wing-body UAV as shown in Figure 1. (a) [8]. The geometry is constructed in CAD application and imported to the COMSOL Multiphysics application. The material used is an Aluminum 3003-H18 which the properties are available in the built-in material of software package.

The mesh used in this study is a half of geometry to save the computational resourse and the UAV is simetric by design. The complete mesh is shown in Figure 1. (b) which consists of 19,169 domain elements, 13,308 boundary elements, and 1,471 edge elements. The minimum quality is $1.238 \mathrm{E}-6$, and average quality is 0.2138 .

The Eigen frequency study used a default setting with 6 desired values and the search method is closest in absolute value.

Table 1- Modal Analysis Result

\begin{tabular}{|c|c|c|c|}
\hline $\begin{array}{l}\text { Mode } \\
\text { No. }\end{array}$ & $\begin{array}{c}\text { Eigen } \\
\text { Frequency } \\
{[\mathrm{Hz}]}\end{array}$ & $\begin{array}{l}\text { Mode Shape/Total Displacement } \\
{[\mathrm{m}]}\end{array}$ & Surface Stress [N/m2] \\
\hline 1 & 278.05 & - & 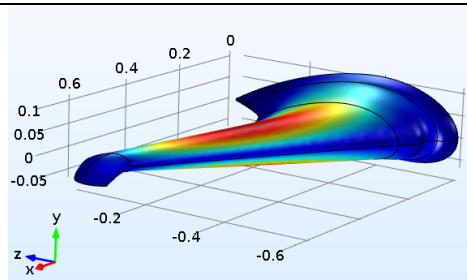 \\
\hline 2 & 721.28 & 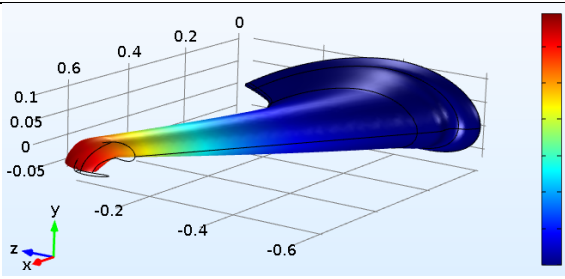 & 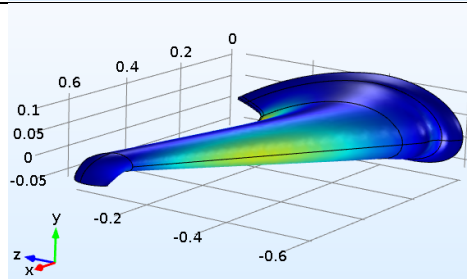 \\
\hline 3 & 816.39 & 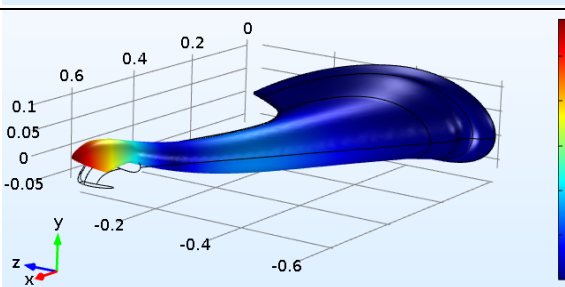 & 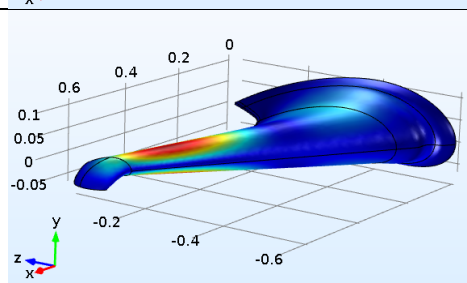 \\
\hline 4 & 1601.7 & $\sum_{-0.2}^{0.4}$ & 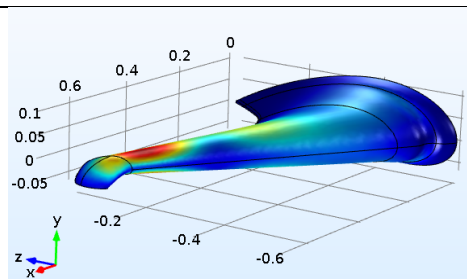 \\
\hline 5 & 1699.5 & 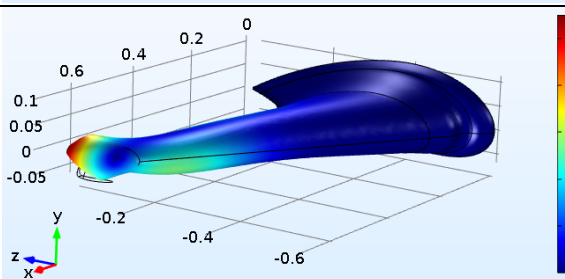 & 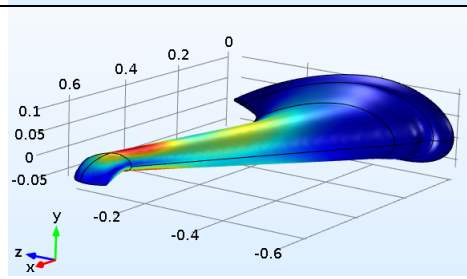 \\
\hline 6 & 1855.5 & $\sum_{\substack{y \\
y=5}}^{0.0 .2}$ & 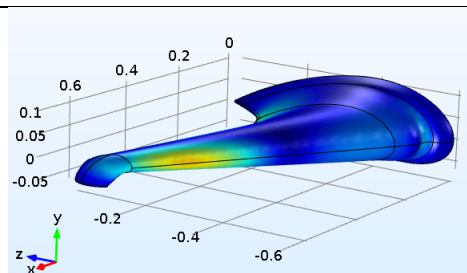 \\
\hline
\end{tabular}




\section{Result And Analysis}

The result of numerical method of modal analysis is presented in Table 1. It consists of 6 eigen frequencies which are $278.05 \mathrm{~Hz}, 721.28 \mathrm{~Hz}, 816.39 \mathrm{~Hz}, 1601.7$ $\mathrm{Hz}, 1699.5 \mathrm{~Hz}$, and $1855.5 \mathrm{~Hz}$. These eigen frequencies correspond to different type of modal shapes and resulted surface stress as shown in the third and last column of the Table 1 . The biggest stress found in modal 1 and the least in modal 2.

The displacement on $\mathrm{X}, \mathrm{Y}, \mathrm{Z}$ axis and total displacement along the leading edge of the body is plotted in the Figure 2 for each of the eigen frequencies.

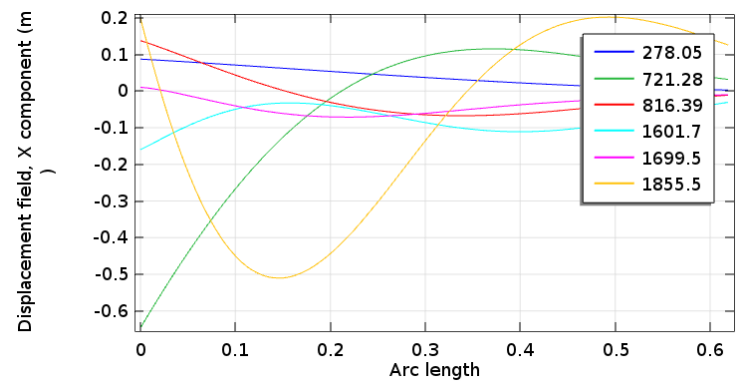

(a)

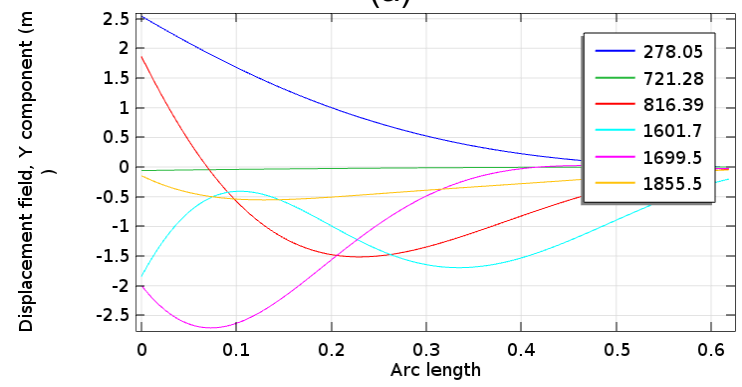

(b)

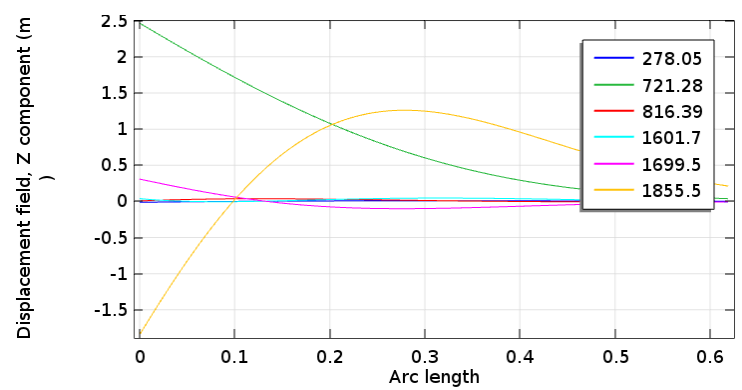

(c)

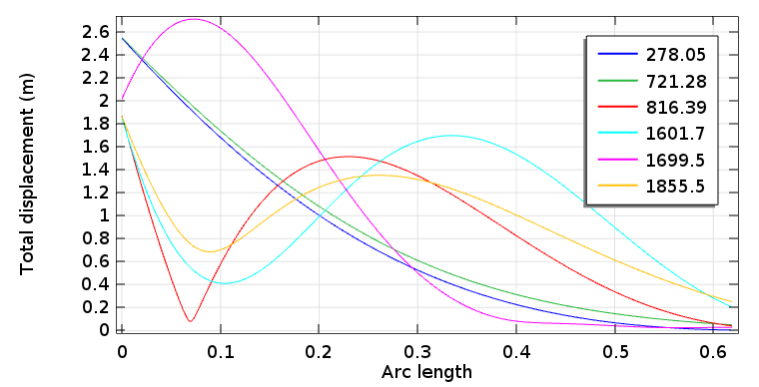

(d)

Figure 2 - Displacement of wing along its leading edge: (a) on X-axis, (b) on Yaxis, (c) on Z-axis, (d) Total displacement

The first modal corresponds to wing updraft movement which result in the highest stress in upper and lower part of the wing. The second modal corresponds to wing swift back movement which result in stress on leading edge of the wing. It was confirmed with the result in Figure 2 that the first eigen value produces large smooth increase movement on $Y$ axis (vertical) in Figure 2. (b) and the second eigen frequency produces large smooth increase movement in $Z$ axis (horizontal) in Figure 2. (c).

The third and fourth modals correspond to the flapping movement on vertical axis. The difference is the third modal has one wave and the fourth modal has two waves as shown in Figure 2. (a) and (b). Although in Figure 2. (b), they have larger magnitude.

The fifth modal is very similar to the fourth modal. However, it is in the opposite direction as shown in Figure 2. (a) and (b). The last modal is a flapping movement on horizontal axis as shown in Figure 2. (a) and (c). Its magnitude is clearly visible in the same Figures as the second modal has significant value, but more waves. However, it has less waves compare to modal 4 and 5. 
Table 2 - Modal Analysis Result of

\begin{tabular}{|l|l|l|}
\multicolumn{3}{|c|}{ conventional wing [4] } \\
\hline & Mode & \multicolumn{1}{|c|}{ Frequency [Hz] } \\
\hline 1 & 1. & 1.3804 \\
\hline 2 & 2. & 6.644 \\
\hline 3 & 3. & 8.3359 \\
\hline 4 & 4. & 22.169 \\
\hline 5 & 5. & 26.056 \\
\hline 6 & 6. & 26.792 \\
\hline
\end{tabular}

Since there is no publication found which evaluate the similar blended wingbody, it is hard to validate the result. However, there is a publication about modal analysis of a conventional aircraft wing made of aluminum [4]. The resulted modals and eigen frequencies are shown in Table 3. The magnitudes are much smaller than our result. However, the proportionality of the frequencies is very similar. It indicates that the modal shapes are similar, however due to the thickness, shape, and length differences, the magnitude of eigen value become different. Hopefully, the resulted eigen frequencies can be used in a design process to prevent flutter phenomenon of the system.

\section{Conclusions}

From the study we can conclude that blended wing-body has:

1. The resulted eigen frequencies are $278.05 \mathrm{~Hz}, 721.28 \mathrm{~Hz}, 816.39 \mathrm{~Hz}$, $1601.7 \mathrm{~Hz}, 1699.5 \mathrm{~Hz}$, and 1855.5 $\mathrm{Hz}$.

2. The modal shapes correspond to the eigen frequencies are updrift, swift back, flapping vertical, flapping horizontal, flapping opposite horizontal and flapping more wave in horizontal movement.

3. The largest structural stress found in the first modal and the least in the second modal shapes.

4. The resulted eigen frequencies are larger than a conventional aircraft wing due to its length, shape and thickness differences.

5. It recommends that different combination of length, shape, and thickness of blended wing-body can be evaluated to understand their effects. Also, external factors could be established to understand the system response to it.

\section{References}

[1] M. Böswald, J. Schwochow, G. Jelicic, and Y. Govers, "New concepts for ground and flight vibration testing of aircraft based on output-only modal analysis," IOMAC 2017 - 7th Int. Oper. Modal Anal. Conf., pp. 18-34, 2017.

[2] E. Neu, F. Janser, A. A. Khatibi, C. Braun, and A. C. Orifici, "Operational Modal Analysis of a wing excited by transonic flow," Aerosp. Sci. Technol., vol. 49, pp. 73-79, 2016, doi: 10.1016/j.ast.2015.11.032.

[3] J. Verbeke and S. Debruyne, "Vibration analysis of a UAV multirotor frame," Proc. ISMA 2016 - Int. Conf. Noise Vib. Eng. USD2016 - Int. Conf. Uncertain. Struct. Dyn., pp. 2329-2337, 2016.

[4] Nikhil A. Khadse and Prof. S. R. Zaweri, "Modal Analysis of Aircraft Wing using Ansys Workbench Software Package," Int. J. Eng. Res., vol. V4, no. 07, pp. 225-230, 2015 , doi: 10.17577/ijertv4is070291.

[5] J. Dimitrijević and P. Kovačević, "Computational Modal Analysis of the LASTA Aircraft," Sci. Tech. Rev., vol. 60, no. 1, pp. 60-69, 2010.

[6] G. Kerschen et al., "Nonlinear Modal Analysis of a Full-Scale Aircraft To cite this version: HAL 
Jurnal Teknologi Kedirgantaraan, Vol, VI No. 2, Agustus 2021, P-ISSN 2528-2778, E-ISSN 2684-9704

https://doi.org/10.35894/jtk.v6i2

Id : hal-01389708 Nonlinear Modal Analysis of a Full-Scale Aircraft," pp. 0-11, 2016.

[7] COMSOL, "COMSOL Multiphysics $5.2, "$ 2021. https://www.comsol.com/ (accessed Jun. 22, 2021).

[8] F. Rafi, "Horten WIP," 2015. https://grabcad.com/library/hortenwip-1 (accessed Jun. 19, 2021). 